\title{
RedPop 2017, a meeting point of cultures and innovations
}

\section{Conference}

Reviewed by

Abstract

Keywords
15TH Congress of the NetWork For Popularisation OF SCIENCE AND TECHNOLOGY IN LATIN AMERICA AND THE CaRIBBEAN (REdPOP), Buenos Aires, Argentina, 21-25 August 2017

\section{Carla Almeida}

Marked by the diversity of initiatives linking science and art and by new presentation formats, the 15th Congress of the Network for Popularisation of Science and Technology in Latin America and the Caribbean (RedPOP) saw heated debates on science, culture, politics and society. Between 21st and 25th August, it brought together in Buenos Aires (Argentina) about 400 participants from 14 countries in order to share new visions, initiatives and research work in science communication. During the event, which included a vast cultural programme, a series of challenges were raised for the future development of the field.

Popularization of science and technology; Science and technology, art and literature; Science communication in the developing world

The 15th Congress of the Network for Popularisation of Science and Technology in Latin America and the Caribbean (RedPOP, http:/ / www.redpop.org) was characterised by the diversity of initiatives linking science and art and by new presentation formats, which, not by chance, favoured creativity. The event takes place every two years in a city of the region. Between 21st and 25th August it brought together in Buenos Aires about 400 participants from 14 countries, including practitioners, researchers and supporters of science communication.

The location chosen to host the event - the Cultural Centre of Science (C3) - was one of the many successes of the organizing committee for this event. Inaugurated in November 2015 as a place of interaction between science and society, the centre counts on a number of spaces for activities and coexistence, in addition to a charming auditorium: the perfect structure to host the stimulating debates that took place during the five days of the congress. Unfortunately, the intense programme, with activities from 9am to $9 \mathrm{pm}$ and a single visit planned to the space, before the official start of the meeting, reduced the opportunities for the participants to get to know what the centre had to offer. 
The opening conference, with a poetic and politically engaged speech by Chiqui González (Minister of Innovation and Culture of the province of Santa Fe), who lulled her teenage daughter in front of a crowded auditorium, followed by an acoustic intervention and a molecular cocktail, contributed to a laid-back atmosphere and a stimulating event.

The plenary sessions were not far behind, provoking reflections not only on the ever more complex relations between science and society, but also on the interactions between science communication and its audiences. How can one turn them into protagonists of their own experience with science? Paola Rodari, from Sissa Medialab (Italy), pointed out some possible paths with regard to science exhibitions. Based on her experience with exhibition spaces, she gave examples of several scientific displays developed jointly with visitors, where barriers between curators, designers and audiences were completely overturned.

During his session, Andrea Bandelli showed how it is possible through art to lead people out of their comfort zone and make scientific developments challenging. Bandelli, the executive director of the Science Gallery International (Ireland), shared some of the institution's exhibition projects that are taken all over the world to generate debate as well as show the political implications of technological advances. Following this provocative line, the Spanish mathematician Eduardo Sáenz De Cabezón, known for his humorous presentations among the scientific monologists of Big Van (http:/ /www.bigvanscience.com), spoke in serious terms about how mathematical knowledge and the use (and abuse) of algorithms are slowly taking control of our lives. It may not seems like it, but math is our problem!

However, it was not only the content of the speeches that stimulated the debate at RedPOP 2017. The new presentation formats, that introduced stories, objects and images as central elements of the communications and reduced the duration of the exhibitions, generated mixed feelings of enthusiasm, doubt and dissatisfaction among participants. Although the novelties did result in more creative and dynamic presentations, they were inadequate with regard to certain aspects. For example, the "ideas at stake" format, which put together in the same room five tables with five "stakeholders" each, could not accommodate listeners and did not follow the schedule provided in the programme, was confusing. The "marathon of ideas", whereby the presenter was given five minutes and three images to share aspects of their work, turned out to be inadequate for research presentations, which, in this format, came across as superficial. Despite the caveats, one must recognise that the new formats have challenged everyone to look at and think about their projects in a different way, an excellent exercise for science communication.

Following the central theme of the congress - Connections: new ways of popularising science - several papers focused on the interactions between science and art. In this area, it is worth highlighting the diversity of cultural activities organised in the name of science communication. Initiatives involving performing arts prevailed, ranging from storytelling to puppet theatre, as well as different genres of music and literature. There were also reports of activities involving games, performances, circus, virtual reality, among many other fun and technological resources. Outside the main theme, there were also works on gender 
and social inclusion. In addition, there was a number of initiatives involving new media and social networks.

As expected, there were fewer research presentations than experience reports and they mostly dealt with more consolidated areas of study in the field of science communication, such as museums, formal and informal education, science journalism and public perception of science. On the other hand, it was possible to notice a growing concern for assessing activities of science popularisation in different contexts and analysing their social impacts, a demand that has grown in the international context of the area. Among the identified shortcomings, the relatively few systematic studies on the interactions between science and art, the use of social media in science communication and accessibility are worth mentioning.

The ups and downs of the research on science communication were debated more broadly and in depth in special sessions promoted by the network of Public Communication of Science and Technology (PCST), the Unesco Montevideo and the RedPOP. The mapping and diagnostics presented within this context pointed out a clearly growing academic field in Latin America, yet still not integrated, with theoretical and methodological weaknesses, little international visibility and reduced political influence. In order to overcome the difficulties, strengthen the area and make it more relevant in the global context, a greater cooperation between the networks committed to the field was endorsed, whereby the characteristics and needs of the region are considered and valued.

During the last special session, when the debate focused on the creation of a political agenda for the science communication in Latin America, Luisa Massarani (Brazil), director of the RedPOP from 2014 to 2017, listed a series of challenges for the network and the development of the area. For example, increasing the reach and social impact of the field, promoting the protagonist role of citizenship in science, consolidating a protocol of assessment of initiatives in the field, supporting the accessibility to science museums, widening the range of offers of practical and academic training in the field. Julia Tagueña, deputy director of the Scientific Development of Conacyt (Mexico), pointed out the importance of considering gender equality as one of the main challenges for the area, which gained considerable support among the participants.

While the scientific programme of the congress triggered stimulating debates about science, politics, art and society, the cultural programme offered moments of beauty, fun and excitement, being one of the highlights of the event. In addition to the opening attractions, participants were treated to two Argentinian works inspired by science which were of high artistic quality: the acrobatic performance Leonardo TP No1, a physical interpretation of texts by Da Vinci, and the musical Christiane, on the life and work of the French-Argentinian researcher Christiane Dosne de Pasqualini. The great impact of these works on the audience of the congress raises reflections on how important random encounters of art with science, outside the context of science communication, can be. In conclusion, a session of scientific monologues on topics as diverse as the composition of atoms, 
the sex organs of sharks, and the effects of neurotransmitters led the audience to a good laugh, while stressing how entertainment can go hand in hand with science communication. Scheduled for the end of the day, the artistic attractions counterbalanced the length of the programme. May Panama, chosen location for next RedPOP congress in 2019, welcome us with so many surprises.

Translated by Sabina Brusemini

Author

Almeida Carla is a journalist specialised in science, with a master's degree (Imperial College London, 2007) and a Ph.D. (Institute of Medical Biochemistry / UFRJ, 2012) in the field of science communication. She works as a researcher at the Research Centre for Science Communication of the Museum of Life / House of Oswaldo Cruz / Fiocruz. E-mail: almeidacarla@gmail.com.

How to cite

Almeida, C. (2017). 'RedPop 2017, a meeting point of cultures and innovations'. JCOM 16(05), R01_en. 